BULLETIN Bulletin hispanique

HISPANIQUE Université Michel de Montaigne Bordeaux

120-1 | 2018

Varia

\title{
Pinceladas autoriales de Torres Villarroel (a partir de dos obras de desengaño)
}

Touches d'auteur chez Torres Villarroel (à partir de deux ouvres de désillusionnement)

The Torres Villaroel author's touch (from two desillusionment works)

\section{Ana Isabel Martín Puya}

\section{OpenEdition}

Journals

Edición electrónica

URL: https://journals.openedition.org/bulletinhispanique/5840

DOI: 10.4000/bulletinhispanique.5840

ISSN: 1775-3821

Editor

Presses universitaires de Bordeaux

Edición impresa

Fecha de publicación: 30 junio 2018

Paginación: 223-238

ISBN: 979-10-300-0298-0

ISSN: 0007-4640

Referencia electrónica

Ana Isabel Martín Puya, «Pinceladas autoriales de Torres Villarroel (a partir de dos obras de desengaño)», Bulletin hispanique [En línea], 120-1 | 2018, Publicado el 01 enero 2022, consultado el 08 enero 2022. URL: http://journals.openedition.org/bulletinhispanique/5840 ; DOI: https://doi.org/ 10.4000/bulletinhispanique.5840 


\title{
Pinceladas autoriales de Torres Villarroel (a partir de dos obras de desengaño $)^{1}$
}

\author{
Ana Isabel Martín Puya \\ Universidad de Córdoba
}

\begin{abstract}
À travers sa longue et complexe production littéraire, Torres Villarroel construit son autobiographie en fonction de sa conscience d'auteur et en réponse aux réactions des lecteurs et des critiques. Cet article traite de la redéfinition de son image à partir de deux œuvres de vulgarisation destinées à dessiller les yeux du grand public.
\end{abstract}

Mots-clés: Torres Villarroel, XVIII ${ }^{\mathrm{e}}$ siècle, auto-représentation, littérature scientifique, carrière littéraire.

A través de su extensa y compleja producción literaria, Torres Villarroel construye su autobiografía desde su conciencia autorial y atendiendo a los feedbacks de lectores y críticos. En este trabajo indagamos en la redefinición de su imagen a partir de dos obras divulgativas destinadas al desengaño del vulgo.

Palabras clave: Torres Villarroel, siglo XVIII, autorrepresentación, literatura científica, carrera literaria.

Torres Villarroel, through his broad and complex literary production, built his autobiography in accordance with his conscience of author and in response to readers and critics feedbacks. In this work, we will study the redefinition of his self-fashioning in two popularization works, written to disabuse the general public.

Keywords: Torres Villarroel, XVIIIth Century, self-fashioning, scientific literature, literary career.

1. Este trabajo arrancó en el Proyecto de I+D Sujeto e institución literaria en la edad moderna (FFI2014-54367-C2-1-R) y se enmarca en la actualidad en el Proyecto Almanaques literarios y pronósticos astrológicos en España durante el siglo XVIII : estudio, edición y crítica (FFI201782179-P) del Plan Estatal de Investigación Científica y Técnica y de Innovación.

Bulletin Hispanique, Tome 120, n 1 - juin 2018 - p. 223-238. 


\section{INTRODUCCIÓN}

La conciencia autorial y la dedicación profesional de Torres Villarroel a la escritura complican el estudio de su obra. Esto es así por la ingente cantidad de publicaciones que produjo, por la variedad genérica y discursiva, y especialmente por el protagonismo que adquiere el yo del autor en las múltiples «máscaras» ${ }^{2}$ bajo las que construye su imagen "pública» y sobre las que sustenta sus estrategias ante los lectores y el mercado. Si es notoriamente conocida y aceptada la ostentación de Torres Villarroel en sus propios escritos, y sobradamente sabida la estrategia de legitimar su figura autorial a partir del éxito de sus impresos en el mercado (especialmente, de sus pronósticos ${ }^{3}$ ) e, incluso, de las críticas recibidas, quizás no se haya insistido tanto hasta ahora, o no se les haya prestado la detenida atención que merecen, en textos del salmantino en los que se presenta a sí mismo como «desengañador» de las mentiras que asume el vulgo sin criterio ni reflexión. Ambas facetas, no obstante, se complementan, y se entrelazan en la delineación progresiva que Torres Villarroel realiza de su persona y de su vida, atendiendo a las críticas recibidas por su dedicación a la "astrología», y en relación con el posicionamiento del individuo en sociedad, frente a quienes pueden rebatirle sus escritos y enjuiciar sus «juicios».

Una vez afianzados el éxito editorial y la fama, Torres decide dar a las prensas su autobiografía para dar clara constancia de «quién es». Sin embargo, si «Torres es autobiógrafo solo porque primero fue astrólogo y escritor popular», y si «La vanidad es la materia prima de su ejercicio profesional ${ }^{4}$, lo lógico es que la Vida se presente como la culminación de la imagen que progresivamente construye a lo largo de toda su obra y que, por tanto, en sus primeros escritos podamos encontrar el germen de ese retrato, que se va perfilando y actualizando con el tiempo (atendiendo al feedback de lectores y críticos).

Entender la obra de Torres como un continuo construirse, sin saltos ni rupturas sino con matizaciones o ampliaciones de su omnipresente figura (personaje, narrador, autor, individuo social), implica reconocer en sus producciones más tempranas ciertos elementos que se mantienen, reconfiguran y actualizan en el conjunto de sus escritos.

Si la creciente incursión de Torres Villarroel en la literatura "divulgativa» puede responder, al menos parcialmente, a un intento por redirigir su imagen, ha de tenerse en cuenta asimismo que su producción está claramente enfocada hacia el mercado, con lo que esto conlleva de necesaria atención al «público» y a sus nuevos intereses. La crítica, aunque sea negativa, supone un reconocimiento

2. Guy Mercadier, Diego de Torres Villarroel: máscaras y espejos, Salamanca, Edifsa, 2009.

3. Sobre los pronósticos de Torres, son de especial interés los trabajos de Fernando Durán López: Juicio y chirinola de los astros. Panorama literario de los almanaques y pronósticos astrológicos españoles (1700-1767), Gijón, Trea, 2015, y «De los almanaques a la autobiografía a mediados del siglo XVIII: piscatores, filomatemáticos y alrededores de Torres Villarroel», Dieciocho, 36.2, 2013, pp. 179-202.

4. Fernando Durán López, «De los almanaques...», p. 191. 
del autor en la república literaria; el público, por su parte, «se convierte en el espejo en el que se mira el escritor» ${ }^{5}$. Y, como acertadamente señaló Álvarez Barrientos,

Escribir pensando en el público suponía cambiar los planteamientos que la mayoría de los sabios y eruditos habían tenido del ejercicio de la literatura, pero también implicaba alterarlos en los científicos, dado el paulatino interés de sectores de población por esas áreas del saber [...] así como en los mismos autores que se dedicaban a la literatura de entretenimiento ${ }^{6}$.

En ambos agentes, por tanto, crítica y público, estaría pensando Torres Villarroel a la hora de escoger la senda de la literatura de divulgación, aunque no por ello se erradique en estos escritos la característica invasión del yo ni la autoproyección del autor. La ciencia se convierte en «vendible objeto de divulgación, y un instrumento para dignificar su personalidad social»; no obstante, «no faltan indicios de una adhesión íntima, de una necesidad existencial de acercarse al conocimiento de la realidad del hombre» ${ }^{7}$.

\section{Orgullo y Conciencia de TorRes: El vulgo, los SABios y la INDEPENDENCIA DE JUICIO}

Atendiendo a la relación de Torres con la ciencia, Pérez López ha señalado que

lo que [...] llama la atención son sus frecuentes gestos de disidencia: sus proclamaciones de empirismo, su adhesión al atomismo, sus guiños distanciadores frente a los excesos anticientíficos del magisterio eclesiástico, sus referencias al sistema copernicano en términos idénticos a los de los novadores ${ }^{8}$.

Efectivamente, podríamos decir que esto llama la atención tal vez por la lectura que durante mucho tiempo se hizo del malquisto Piscator, aunque también por el hecho de que alcanzara el éxito, inicialmente, por su condición de astrólogo.

Ya en sus primeros escritos se desmarca el salmantino de las críticas y el descrédito que merece esta profesión, no solo mediante las continuas alusiones al oficio de Piscator como medio de solventar sus necesidades económicas (y con menciones reivindicativas de la fortuna de sus almanaques), sino también

5. Pedro Ruiz Pérez, «El sujeto autorial dieciochesco: a partir de una Fama póstuma», en Ser autor en la España del siglo XVIII, coord. Elena de Lorenzo Álvarez, Gijón, Ediciones Trea, 2017, pp. 479-508, p. 493.

6. Joaquín Álvarez Barrientos, Los hombres de letras en la España del siglo XVIII: apóstoles y arribistas, Madrid: Castalia, 2006, p. 80.

7. Manuel M.a Pérez López, «Para una revisión de Torres Villarroel», en Revisión de Torres Villarroel, ed. Manuel María Pérez López y Emilio Martínez Mata, Salamanca, Universidad de Salamanca, 1998, pp. 13-35, p. 19.

8. Manuel María Pérez López, op. cit., p. 21. 
en tanto que desde sus mismos pronósticos «establece un juego entre su diestro arte de vaticinar el futuro, y una perpetua burla de sí mismo y de sus augurios» ${ }^{9}$.

La autolegitimación continúa, como es sabido, en papeles expresamente destinados a la contestación de sus censores (escritos siempre recubiertos del peculiar estilo jocoso del salmantino). Así, por ejemplo, en 1725 publica los Desprecios prácticos de los prácticos avisos de D. Jerónimo Ruiz de Benecerta (Madrid, 1725), donde avanza en la construcción de su imagen y en la vindicación de una mentalidad "moderna» (entendamos, en este caso, de su tiempo). En este, Torres responde a las críticas, impresas bajo pseudónimo, al prólogo del almanaque aparecido a finales del año anterior ${ }^{10}$. El salmantino dedica su contestación «a los señores majaderos, tontos, ignorantes, salvajes y necios del mundo", que no son sino los pobres lectores que compran sus escritos, que le otorgan la fama y el dinero, los «seńores majaderos de mi alma», su mejor defensa ante las críticas que recibe. A estos contrapone los discretos, tan «enamorados de sus cabezas» que no perdonan ningún error ni nunca callan sus críticas. Apela, pues, Torres, como en tantas otras ocasiones, al tan denigrado vulgo ignorante (ante el que se disculpa por haberle temido previamente), su aliado y protector ante esos sabios, que son, para el autor, los verdaderos necios: «los necios son los que el mundo llama sabios, y estos son discretos por mal nombre» $(2 \mathrm{v})$.

Torres aprovecha este llamamiento a su "público» para anunciar cierta irreverencia ante las autoridades de los sabios basándose en la multiplicidad de criterios, en la diversidad de opiniones y en sus continuas disputas: "Los doctos, en fin, tienen dudosas las doctrinas, en cuestión las verdades, y lleno de gritos y porfías el mundo» (f. 2). Si esto guarda relación con su oposición al escolasticismo dominante en las universidades y aparece ya en el mencionado paratexto del almanaque para el año de 1725, insiste aquí Torres para afirmar que por este motivo descree de la letra impresa y prefiere fiarse de su propio juicio: «Mi pecado todo es no tener fe con los hombres ni con sus escritos; no tengo yo culpa, sino los libros que he leído» (p. 1). Aunque tales conclusiones vienen sustentadas por lecturas de amplia tradición, como las Confesiones de san Agustín o los escritos de Quevedo, invalida Torres, no obstante, el principio de autoridad en lo que se refiere a las letras humanas y a las ciencias, puesto que "todos somos vanidad y presunción», incluidos aquellos que adelantaron las leyes, la medicina y la filosofía. Deslegitima, así, a Justiniano, Galeno y Aristóteles, y pone todo en duda salvo «la verdad de las verdades» (p. 3) ${ }^{11}$. Pero

9. Fernando Durán López, «De los almanaques...», p. 185.

10. Diego de Torres Villarroel, «Torres a su pronóstico», Academia poética astrológica sobre el juicio del año de 1725, [s.l], [s.i], [1724], 7v-10v. El papel que responde a este prólogo es Prácticos avisos. Con que el pronóstico de Salamanca de este año de 1725, instruido de los lectores, corresponde a su padre y autor, el bachiller don Diego de Torres. Sácalos a luz don Jerónimo Ruiz de Benecerta, Madrid, Francisco Martínez Abad, 1725.

11. A esto ha de añadirse que «la desdicha de las profesiones, además de ser todas conjeturables, consiste también en que nosotros las hacemos viles: no las profesamos para ser doctos, sino para comer» (Desprecios prácticos..., p. 27). 
esto vale, según señala, para sus propios escritos, pues afirma ser «el primero que abomina la vanidad de mis conjeturas, lo incierto de los juicios», lo que no le impide considerar los principios matemáticos (de su ciencia) demostrables.

Esta irreverencia de Torres ante las autoridades se comprueba en obras posteriores. La misma profesión de fe que a otros les permitirá negar o censurar la «curiosidad» de los «modernos» hombres de letras (el estudio de la naturaleza, etc.) le valdrá a Torres para reforzar su afirmación de independencia de juicio y su propia capacidad de raciocinio. Si la única verdad son las Sagradas Escrituras y los diez mandamientos, ¿por qué ha él de atarse a lo que dijeron los antiguos, hombres como él y, por tanto, imperfectos? ¿Por qué creer las mentiras de otros si puede crear las suyas propias (a partir de un discurso apegado a lo tangente, práctico y demostrable)? Torres acepta pequeñas verdades «básicas», obvias, comprobables mediante la experiencia, y a partir de ellas construye su propio razonamiento y extrae conclusiones cuya verdad o imbatibilidad no defiende hasta el extremo; más bien, por el contrario, relativiza su valor, deslegitima con frecuencia (aunque sea estratégicamente o para neutralizar las críticas) sus resultados. Si bien esto, por un lado, puede parecer consecuente con la concepción que expone acerca del hombre, de la vanidad y del conocimiento, por el otro, le permite mantenerse en ese juego de ambigüedad con que construye su obra y se representa: el estilo jocoso que todo lo invade, incluida su propia persona, que se mueve entre la reivindicación y la autoburla.

Sacudido el salmantino por los juicios de quienes lo tachan de ignorante por su dedicación a la astrología, su defensa no solo incorpora el reconocimiento del carácter lúdico-festivo que impregna sus pronósticos, sino que recoge la distinción entre astronomía, filosofía natural y astrología judiciaria ${ }^{12}$ : esta, sí, censurable; esta, sí, condenada. Pero el Piscator defiende que los campos que corresponden a su oficio y a sus almanaques son los dos primeros, de amplia trayectoria y reconocimiento, y acusa de necio al tal Benecerta por ser incapaz de distinguirlas.

\section{DivUlgaCiÓN CIENTÍFICA Y AUTORREPRESENTACIÓN}

La avalancha de críticas recibidas por el Torres almanaquero, convertido entre ciertos sectores de erudición en objeto de escarnio y burla, será asumida, pues, por el salmantino para reconfigurar su imagen pública en escritos posteriores. $\mathrm{Si}$ de estos forman parte papeles nacidos de manera explícita en respuesta a juicios censores recibidos, no es menos cierto que otros papeles, de aspiración divulgadora, vindican la faceta desengañada y cientifica del catedrático de Salamanca, que ofrece sus juicios para liberar de los errores y supersticiones al vulgo, constituido no solo por la plebe, sino también conformado por supuestos eruditos apegados a la opinión común. Así pues, en estas obras, al tiempo que se reafirma Torres en las tendencias que comienzan a extenderse entre ciertos

12. D. de Torres Villarroel, ibid., pp. 33-35. 
hombres de letras contemporáneos, sumándose al mediático propósito de la instrucción pública, afina el dibujo de su figura autorial y se posiciona en la legitimación de las nuevas prácticas de pensamiento cientificista, basadas en la experiencia y en la razón. Todo ello lo hará sin soslayar el protagonismo que el yo adquiere en el conjunto de sus escritos, sin abandonar la ostentación ni la reivindicación continua en que muestra su conciencia autorial.

La faceta «divulgadora» de Torres se inicia tempranamente con el Viaje fantástico (1724) y se intensifica con el paso de los años, con frecuencia en obras de marcado carácter literario; en ocasiones, en tratados de apariencia más «seria», pero siempre con un descuello importante del omnipresente Torres Villarroel. Si la estrategia editorial del salmantino pasa por la explotación lucrativa de la superstición, no es menos cierto que se incorpora a la misma también la explotación del desengaño «ilustrado». Los opúsculos divulgativos se sitúan, no obstante, entre la empresa comercial, el lavado de su imagen y un afán divulgador acorde a su tiempo ${ }^{13}$.

El intento de delinear su figura pública a través de impresos científicos de carácter divulgativo condice con su aspiración a (re)presentarse ante sus lectores (a la altura de $1752^{14}$ ) como «hombre instruido, que conoce la ciencia y que la enseńa tanto en las aulas como en las academias de mayor prestigio y notoriedad», como «una suerte de ilustrado que despierta al país de la ignorante somnolencia en que se encontraba $»^{15}$. El Torres almanaquero y poeta enfoca así su imagen no solo hacia la empresa comercial, sino también hacia la utilidad pública, en estrecha relación con su independencia y autonomía de pensamiento, que le permiten situarse a contracorriente del escolasticismo y la retórica huera de un periodo decadente de las ciencias y la educación.

\section{Poeta social, almanaquero profesional y científico racional}

Esa doble cara de poeta (social) y almanaquero «profesional», con ánimo de lucro y alarde de entretenimiento, ya había sido destacada por Torres en el temprano Correo del otro mundo:

Yo tengo dos oficios y con ambos me muero de hambre, pero el más decente es el de poeta, que el de astrólogo me ha ganado créditos de embustero; y este es oficio, y no ciencia, pues hoy pagan tributos mis calendarios, y mis coplas, aunque no son nobles, no pechan ${ }^{16}$.

13. Véase Joaquín Álvarez Barrientos, Los hombres de letras...

14. En el «Prólogo general» de sus Obras completas (Diego de Torres Villarroel, Libros en que están reatados diferentes cuadernos físicos, médicos, astrológicos, poéticos, morales y misticos..., vol. I, Salamanca, A. Villagordo y P. Ortiz Gómez, 1752, ff. 19-24). Puede leerse también en Torres Villarroel, "Corpus autobiográfico», pp. 416-421.

15. Ignacio García Aguilar, «Carrera literaria e imagen autorial en Diego de Torres Villarroel», en Ser autor en la España del siglo XVIII, edición de Elena de Lorenzo Álvarez, Gijón, Trea, 2017, p. 147.

16. Diego de Torres Villarroel, Correo del otro mundo al Gran Piscator de Salamanca. Cartas 
Exponía en este impreso, asimismo, su punto de vista ante los libros y la ciencia, además de una nítida figura de su yo ficcionalizado. En esta obra se sitúa en un espacio de disidencia, marginal, en tanto que independiente, con respecto al campo literario de su época, otorgándose a sí mismo un toque de distinción a partir de esa orgullosa vindicación de su originalidad, que le hará poner el acento en su desmedida imaginación, tan exacerbada (tan natural en él que es presentada como una inclinación incontrolable) que linda con la locura: "Para hacer lo que todos, no hubiera yo salido a la plaza del mundo, porque estoy mal con los escritores de mi siglo, pues no inventan, que trasladan» (p. 16).

Pero, si la libertad de Torres se la da su éxito editorial, la independencia no responde únicamente a su capacidad imaginativa, sino a su libertad de juicio, a su combinación con el entendimiento y su capacidad de raciocinio, apegada en él a lo tangible y experienciable, que le permita ser considerado hombre de letras y hombre de ciencia. Esto estará relacionado, a su vez, con el concepto que defiende del propio ser humano y de la incapacidad de certezas intangibles, con su desconfianza y descreimiento, con su deslegitimación de las autoridades escriturarias, con su incredulidad generalizada: "Yo no soy satírico, sino incrédulo, duro; que al que no me venga con la demostración en la mano no lo creeré por cuanto me jure, afirme y asegure». La única verdad que afirma es la de «nuestra santa fe» (p. 17); para el resto, apela a la razón y a la experiencia.

La construcción conceptual de su «descreimiento» de las autoridades, o al menos relativización de las verdades contenidas en los textos, puede ponerse en relación con algo que mucho antes había indicado Huarte de San Juan:

la verdad no está en boca del que afirma, sino en la cosa de que se trata [...] El que tuviere docilidad en el entendimiento y buen oído para percibir lo que Naturaleza dice y enseña con sus obras aprenderá mucho en la contemplación de las cosas naturales, el que no, terná necesidad de preceptor que le avise y le haga considerar lo que los brutos animales y plantas están voceando ${ }^{17}$.

El valor que la originalidad ha ido adquiriendo como medio de distinción se conjuga en Torres con esa vindicación de la propia capacidad racional, vinculada a las nuevas corrientes del pensamiento científico (o cientificista). Imaginación y fantasía se unen a la defensa de una metodología empírica y experimental que alienta la capacidad de generar un discurso autónomo, cuyo punto de partida es, como apunta el difunto Hipócrates en la carta que Torres le atribuye en Correo del otro mundo, la razón:

El aplicado debe estudiar primero en los libros de su razón, y después seguir las huellas de todos: el camino del médico, la senda del filósofo, el vuelo del teólogo, la carretera de la plata del letrado, los rincones del químico y los escondites del mecánico

respondidas a los muertos por el mismo Piscator, D. Diego de Torres Villarroel, profesor de filosofía y matemáticas, etc., Sevilla, Diego López de Haro, 1725, p. 16.

17. Juan Huarte de San Juan, Examen de ingenios, ed. Guillermo Serés, Madrid, Cátedra, 1989, pp. 194-196. 
[...] El saber es lo que hace este muchacho del prólogo [Torres], encargarse de los elementos de todas las facultades. Estudiando después en su razón natural, se vandeará e instruirá en todas las profesiones, averiguando el modo con que todos mentimos y pasamos $^{18}$.

Como vemos, Torres pone en la pluma de Hipócrates la autolegitimación de su método y de su escritura a partir de una concepción relativista, manifiestamente descreída, de la posibilidad de verdades al alcance del hombre, cuyos «supuestos y sus libros, sus presunciones y fantasías, no hay diablos que me las encajen». Esta misma actitud le permite afirmar, en respuesta a Papiano, que "para demostrar el mundo no es necesario leer, sino ver. Más enseña el trato que los libros; estos son cuerpos muertos, y el trato, voz viva, y en lo que tocan los ojos, son odiosos los argumentos» (p. 35).

La decantación y el gusto por lo conversacional aquí sugeridos aparecerán reformulados en su Desengaño razonable. Pero antes de abordar esta obra, conviene que prestemos atención a otro de esos papeles de «utilidad pública» redactados para instrucción del vulgo, beneficio económico y proyección personal.

\section{LAS ObRas DE «DESENGAÑO»: TORRES CONTRA LOS TEMORES DEL VUlgo}

Las Noticias alegres y festivas de las ráfagas de luz que se vieron la noche 16 de diciembre sobre nuestro horizonte ${ }^{19}$, aparecidas en 1737 o principios de 1738, son escrito significativo, compendio de ese intento torresiano de corregir o redirigir su imagen pública, de dignificarla sin perder los aspectos que le habían valido su éxito y su fama. Este impreso recoge en sí mismo las principales vías de la autorrepresentación y estrategia de Torres: las dos vertientes principales, los dos oficios conocidos del Piscator, el de poeta y el de astrólogo, aparecen representados y burlados. Su crédito y su difamación provienen de ambos, a los que se añade en el compendio la cara de «instructor de cultos» ${ }^{20}$, de desengañador de las supersticiones a partir de su adscripción al pensamiento científico.

Independientemente de que hubiera o no una verdadera intención divulgativa, Torres pretende compensar su descrédito y dignificar su figura haciéndose no solo acreedor de unos conocimientos "científicos", sino presentándose, además, como batallador contra los miedos y supersticiones que los fenómenos naturales causan en el vulgo. Fomenta, al mismo tiempo, su

18. Diego de Torres Villarroel, Correo..., pp. 19-20.

19. Diego de Torres Villarroel, Noticias alegres y festivas de las ráfagas de luz que se vieron la noche 16 de diciembre de 1737 sobre el horizonte de Madrid. Respuesta de don Diego de Torres en verso corriente, prosa pura y filosofía clara, como Dios la crió, sin las inmundicias y mezcolanzas de las voces griegas y castellanas de Tetuán, a una carta de una dama, deseosa de saber la naturaleza, impresión y pronóstico de ese fantasmón aéreo a quien han querido llamar fenómeno los descomulgados del buen lenguaje, Sevilla: Imprenta Real de don Diego López de Haro, [1737-1738].

20. Ignacio García Aguilar, «Carrera literaria...», p. 148. 
propia percepción como descreído y risueño autor con pinceladas de un estilo jocoso que alternan con la mayor "seriedad» expositiva en los momentos clave de su «demostración» razonada.

En la portada se anuncia que el escrito responde "a una carta de una dama deseosa de saber la naturaleza, impresión y pronóstico de ese fantasmón aéreo a quien han querido llamar fenomeno los descomulgados del buen lenguaje». Torres se presenta así como autoridad en la materia a quien le ha sido solicitado su juicio al respecto, no obstante lo cual, en la dedicatoria confiesa que la destinataria del papel es «inventiva que escogió mi ingenio para hacer menos desabrida la lectura».

Pese a que el Piscator anuncia el propósito informativo e instructivo del impreso, su orgullo autorial se hace patente no solo en el tratamiento del tema, que, en tanto que astrónomo, podría considerarse que le corresponde, sino también en la presencia de ciertos elementos característicos de su obra y en la estructura misma del texto "divulgativo». Así, cabe señalar que tras la dedicatoria (que, como es costumbre en Torres, incorpora un remarcable componente autobiográfico, y en la que manifiesta hallarse en boca del vulgo - «O ya político, o ya popular» ${ }^{21}-$ ) se introduce el «Prólogo sesenta y seis» (indudable muestra jactanciosa del orgullo de una trayectoria).

La característica recurrencia de Torres al prólogo como medio de autoproyección y de diálogo continuado con su "público» es asumida por el autor como condición personal y esencial casi de su obra. El prólogo es espacio propicio para la defensa ante el lector-censor y para pretender la complicidad del lector-amigo. Ambos, de una u otra manera, le resultan beneficiosos, y a ambos se dirige explícitamente en este caso. Los primeros aparecen como autores, a su vez, de sus propios "papelones y boberías», y ante ellos reivindica Torres exaltadamente su libertad e independencia como escritor (de «disparates»): «yo me lo escribo, yo me lo leo y yo me lo trago sin consulta de nadie y sin más consejero que la buena ventura de mis disparates y el precepto que me insta a todas horas a que huya de la ociosidad» (p. 5).

Ante esos críticos justifica el empleo de un lenguaje alejado de la "greguería» de los físicos, es decir, prioriza la claridad lingüística de su discurso sobre la presunción o la apariencia de conocimiento, puesto que el vulgo (ese lectoramigo) es el destinatario de sus escritos,

porque este es el que desea informarse de esta novedad, este es el que está asustado, a este es a quien he de sacudir el polvo del espanto y la ignorancia, y a este debo contentar (aunque me lo regañen los críticos), porque entre su divulgada familia andan también de tapadillo muchas personas de gusto y de razón (p.5).

Si previamente distinguía entre un vulgo político y otro popular, ahora parece apuntar la diferencia entre la consideración social y el conocimiento, entre la apariencia de erudición y la razón.

21. Diego de Torres Villarroel, Noticias..., 2r. 
La introducción de la utilidad de su escrito y la notación directa del destinatario del mismo da paso a la acostumbrada reivindicación de la fortuna y divulgación de las publicaciones del autor, unida ahora a la «incredulidad» ya mencionada acerca de la posibilidad de alcanzar verdades, asumida, como dijimos, también en el caso de los escritos personales:

Lo cierto es que todo lo que he escrito hasta ahora son boberías e ignorancias. Bien quisiera escribir discreciones y verdades; pero, como soy hombre, que lo tengo por imposible. Yo bastante me acuso, me maltrato y me satirizo, y así me quieren y así me compran aun los que no me conocen ${ }^{22}$.

Esta concepción del ser humano permite la autoexculpación de las acusaciones a sus escritos haciéndolas extensibles a todos los demás autores. La autocrítica fundamentada sobre una imposibilidad general se convierte en legítima defensa.

A partir de aquí, Torres fortifica su alegato mediante la apelación directa al otro, al lector-amigo (su principal fuente de ingresos y de legitimación), dotando a su discurso de un tono burlesco para recurrir a ciertos componentes bien conocidos de su estrategia: la vindicación de su éxito y fama a partir del rédito de sus impresos y del apoyo de su público, y la mofa y deslegitimación de sus contrarios, tratados como pobres presuntuosos que aspiran a una ganancia económica para ellos inalcanzable mediante la escritura. Si en Desprecios prácticos Torres se parapetaba tras sus «queridos majaderos», ahora les pide socarronamente que compren los papeles de sus contrarios - para que no mueran de hambre y para que dejen de escribir locuras-, porque él ya no necesita de nadie para su sustento.

Una vez cumplida la de prologuizador incansable, el cuerpo textual de la Noticia festiva nos va a mostrar las otras facetas del afamado Torres. No renuncia el salmantino a incorporar en su divulgativo papel un romance burlesco mediante el cual, a la vez que se retrata y explota sus caras de poeta y astrólogo, se mofa de los temores extendidos entre el vulgo y desmiente la posibilidad interpretativa del fenómeno desde la superstición a través de la multiplicidad de causas, justificaciones y vaticinios que le atribuye, desde una mirada literaria que juega con los valores disémicos de los significantes, desde la risa.

Concluido el romance y depurado el «frenesí poético» de Torres, comienza en prosa su exposición "científica» del suceso, no sin antes advertir que «ningún filósofo puede responder con juicio de la certeza de semejantes visiones, aunque estudie sobre ellas hasta el día del Juicio» (p. 4). En estructura similar (o asimilable) a la del romance, el salmantino divide su exposición en tres apartados: «Lo que vi», «Lo que discurro» y "Lo que pronostico». Torres parte de la observación, indaga en las causas a partir de sus conocimientos científicos y construye sus pronósticos a partir del origen natural que atribuye al fenómeno ${ }^{23}$.

22. Diego de Torres Villarroel, ibid., 3r.

23. Así, por ejemplo, la descripción de lo que Torres vio se ciñe a lo empírico («un nubarrón 
En la Noticia festiva conjuga Torres, por tanto, sus diversas facetas (tras explotar la de prologuista desenfadado y autorreivindicativo): la de poeta imaginativo y burlón, la de astrónomo conocedor de los fenómenos naturales y la de pronosticador, pero, eso sí, "científico», alejado de conjeturas vanas y supersticiones carentes de lógica «natural». Las interpretaciones que ofrece Torres están ceñidas a la búsqueda de una explicación racional y científica. No entraremos ahora en si sus «juicios» eran acertados o erróneos, ya que a la altura de 1737 lo significativo es la «intencionalidad», la mentalidad o las pretensiones cientificistas, más que la eficacia de los razonamientos. Otro aspecto nos interesa, y es que, al paso de su discurso, introduce el Piscator una nueva pincelada autobiográfica y estratégicamente reivindicativa de la imagen propia, iniciando de este modo «Lo que pronostico»:

Muchos salvajes de los que andan en compañía de los hombres me han graduado de pronosticador melancólico y agorero de infelicidades, y es tan al contrario que creo que no ha nacido en Espańa astrólogo tan de castañuela como yo. Al son de la burla que echo de mis pronósticos estoy bailando toda mi vida. ¿Cuántas veces he soltado las carcajadas contra los que han creído a mis diarios y aun a mis diaristas? ¿Nada basta si yo tan presto escribo verso como prosa, medicina como teología, física o ética? ¿Por qué me han de tener por puro pronosticador? [...] a mí nadie me da nada por que calle, por que grite o por que escriba a su gusto, y el pronóstico me da mucho más de lo que merezco y de lo que valen cuantos lo murmuran, que ya sé que son los discretazos físicos, almanaqueros recientes, escritores comidos de polillas que andan por ese mundo enredados en trampas, pingajos y remiendos, roídos de los piojos, llenos de envidia y vacíos de panza, y, finalmente, atenidos los más a las migajas del triste bodrio de mi astrología y mi gramática. He de pronosticar hasta que Dios me llame a juicio y a ellos se lo dé24.

Introduce entonces sus habituales predicciones en función de lo que considera filosofía natural: sequedad en el aire y sequedad en los cuerpos (racionales, brutos y vegetales), aconseja cómo proteger plantas y animales, y ofrece algunos consejos a los médicos. Finalmente, da indicaciones a la señora, antes de insistir en la idea de la imposibilidad de conocer lo que pasa «de tejas arriba ni de tejas abajo. Esto es verdad, y no lo es lo que presumen algunos vanos e ignorantes escritores y leyentes» (10).

Similar estructura a la del discurso en prosa de las Noticias encontramos en los Desengaños razonables ${ }^{25}$, donde Torres se presenta, a medio camino entre la humildad y el posicionamiento autorreivindicativo, como recientemente convertido a una independencia de juicio y descreimiento

rojo y encendido, de forma irregular», etc.); en «Lo que discurro» concluye que «No puede ser otra la causa de ese iluminado promontorio que la demasiada sequedad del año» (80), etc.

24. Diego de Torres Villarroel, ibidem, p. 9.

25. Diego de Torres Villarroel, Desengaños razonables para sacudir el polvo del espanto y del aturdimiento que ha producido en los espiritus acoquinados el cadáver de don Roberto Le Febvre Dumolinel, cadete de las reales guardias de corps, por haberle visto flexible y sudando, después de algunos días expuesto en un salón del Hospital General de Madrid. Los escribe, para que se limpien de sus admiraciones y sustos los genios atolondrados y los fisicos de cortos alcances..., Sevilla, Diego López de Haro, 1747. 
de los engańos corrientes y comunes entre los ignorantes. Tal afirmación habilita la contraposición entre un estado de inmadurez, ya pasado, y un presente de "reverendas canas y cetrinas arrugas», en el que logró «el olvido, la abominación y el desengaño de semejantes embelecos». Es decir, al asumir su anterior disposición crédula y supersticiosa, reivindica su actual «sabiduría» y conocimiento, que va a fundamentar sobre una capacidad de raciocinio y criticismo independientes que parten de su «experiencia» y "cuidado» (p. 3). Situado, pues, en una etapa de madurez, Torres se dispone a poner su discurso al servicio del destierro de prejuicios «vulgares» (en tanto que «comunes» de los "genios atolondrados y físicos de cortos alcances", señalados como objetivo de sus instructivas palabras en la portada).

Pero no se va a referir el catedrático de Salamanca únicamente a los cuentos y creencias populares a que alude inicialmente en la autoinculpación de su yo en pañales, sino que su «inocencia» será asimismo probada por su creencia de "que había medicina en el mundo, y que los hombres que comercian y comen de los dolientes sabían curar todos los desgarrones, quiebras, desmadejamientos y precipicios de nuestra salud» (4; el subrayado es nuestro). A esa conciencia de lo que de oficio tiene la práctica médica, como medio de subsistencia que convierte al enfermo en objeto de enriquecimiento, se añade la iluminación, el destierro del error mediante la propia experiencia (el padecimiento, físico y personal, de la ineficacia e ignorancia de los doctores), pero, especialmente, la «amorosa luz del desengaño" alcanzada haciéndose "ladrón de casa» (p. 4), es decir, introduciéndose en el mundo de la medicina, adquiriendo los conocimientos y las prácticas de los doctores. La experiencia se duplica, por tanto, al añadirse a la de los efectos la propia conversión del autor en doctor. Torres se autolegitima como crítico de los médicos, puesto que nace su impugnación de una certeza fehacientemente comprobada en primera persona, que le lleva a descubrir «sus drogas, sus marañas y su negociación, que toda se reduce a persuadir que saben lo mismo que ignoran» (4; el subrayado es nuestro) ${ }^{26}$.

La medicina como creencia, como ciencia engańosa sostenida sobre la apariencia y la finalidad mercantil, se va a oponer a las matemáticas, disciplina con la que se identifica Torres y que toma como fuente de conocimiento demostrable y seguro; de este modo, el salmantino dice descreer en el presente de todo aquello que, percibido por los sentidos (suyos o de otros), «no traigan testimoniados los objetos y las relaciones con doscientos testigos que juren matemáticamente sobre los libros de Euclides en su demonstración» (p.4; el subrayado es nuestro).

Plantea de este modo Torres la oposición entre lo engañoso y lo científico, situándose él mismo en este polo de la dicotomía, lo que le habilita no ya para desmentir la divulgada «historia del guardia de corps que daba sangre y sudor después de amortajado» -que se había resistido a creer, «aunque lo vi de letra de molde y con las licencias necesarias» (p. 4)-, sino para, una vez asegurado de la

26. No podía faltar el haber visto morir a tantos pacientes, «con más dolor, fatiga y ligereza» por estar en manos de los doctores (p. 4). 
veracidad de los hechos (por el fiel relato que don Luis Antonio de Mergelina y Muñoz, administrador del Hospital General de Madrid, envió a don Fernando Triviño), discurrir «sobre el caso», es decir, ofrecer su lectura del mismo y desterrar las causas sobrenaturales a que se atribuye. El propio desengaño de Torres respecto a sus creencias pasadas le lleva ahora a desautorizar los juicios insertos en los libros, por lo que se limita a transcribir la carta de Mergelina a Treviño (para que «nos sirva su erudita verdad de norte») y a trasladar «lo que yo he pensado [...] ceñido a la siguiente relación» (p. 5; el subrayado es nuestro).

Cuando Torres señala que prefiere aprovechar su visita a la corte para ver y conversar con sus amigos, de cuya compañía disfruta más que de los libros, que pueden llenarle la cabeza de mentiras ${ }^{27}$, y que le resultará más provechosa (como aprendizaje), no solo está desacreditando la autoridad de lo impreso y reivindicando su libertad de pensamiento y discurso (raciocinio), sino que está también adhiriéndose a los hábitos sociales e ideológicos desarrollados en el XVIII, en que se reviste de cierta aura el concepto mismo de amistad y cobran presencia y valor la conversación y la relación directa entre los integrantes de la República de las Letras ${ }^{28}$.

En su relación, Mergelina describe fielmente el suceso y considera que, dada la conocida virtud del fallecido, «No es ligereza ni falta de severidad persuadirse a que el dicho fenómeno le haya producido la gracia» (p. 7). Para Torres, sin embargo, atribuye esta consideración a "prontitud devota", poca observación $\mathrm{y}$ "conocimiento" del cuerpo humano y «mucha miseria de nuestra filosofía». Compara el del cadáver del guardia con otros casos «que creyó el vulgo como irregulares y portentosos», pero, "reducidos al examen», se descubrió que sus causas eran naturales (p. 8). Así pues, aunque se protege de posibles represalias al aceptar la existencia o posibilidad de milagros, defiende que, como va a hacer él, se ha de tratar de explicar este tipo de hechos como resultado de procesos naturales (p. 9).

Más adelante, como conclusión de su misiva, insistirá sobre esta cuestión: «No es mi ánimo derribarlo totalmente de milagro [...] sino prevenir que para milagro tiene muchas equivocaciones con la naturaleza, y para que los casos sean de altura milagrosa han de presentarse a nuestra vista y conocimiento limpios de todo lo posible de tejas abajo» (p. 16).

Para Torres, que expone en su discurso posibles motivos de la incorrupción del cuerpo del guardia, a los que se añaden «otros muchos que se pueden sacar de las mismas cosas que cada día vemos, tocamos y oímos» (p. 15), son «los genios piadosos y desaplicados» (p. 10), «la vulgaridad mentirosa y aturdida (además de la verdadera relación del Sr. D. Antonio Mergelina)»(p. 11), quienes atribuyen al suceso causas sobrenaturales; pero el caso se puede explicar

27. Se decanta por no desperdiciar el breve tiempo que pasará en Madrid en la consulta de libros, que «tal vez me pondrían en la pluma otros mentirones tan garrafales como los que me puso en el pico de la oreja la vejancona que me crio", y disfrutarlo, por el contrario, «en servir y conversar con mis amigos, pues lograré más gusto y provecho con su conferencia» (p. 5).

28. Joaquín Álvarez Barrientos, Los hombres de letras..., p. 30. 
relacionándolo con ejemplos cotidianos «que omito porque no hay rústico que no los conozca» (p. 12) y a partir de efectos que "el más ignorante sabe» (p. 13).

$\mathrm{Al}$ excurso inicial en que se distingue entre su pasado ignorante y crédulo y su escepticismo presente se añade la aparición de la característica voz autorial en su «desvío» hacia un estilo desenfadado para burlarse de la asociación del «milagro» con la excelsa virtud del finado, en que aprovecha, además, para incorporar la alusión a su oficio como astrólogo, implícita en la finalización de su discurso con el "pronóstico» racional de la «evidente» respuesta fisiológica de su propio futuro cadáver:

Yo, Sr. mío, fui y soy el hombre más malvado del mundo, y si en enfriándoseme el cielo de la boca me ponen parente a la inclemencia, desde ahora pronostico que han de dar mis zancarrones más brincos, pernadas y carreras que nuestro finado (p. 11).

Como vemos, tanto en las Noticias como en los Desengaños razonables adopta Torres una actitud empirista mediante la cual trata de explicar fenómenos naturales que gozan de una divulgada lectura «mágica». Estas dos obras pueden servirnos como ejemplo de las que podríamos considerar «de desengaño», con las que se acerca Torres a las tendencias del pensamiento de su época, y con las que trata de sobreponerse ante quienes lo acreditan de ignorante. Como todos los escritos del salmantino, se ven atravesadas por la figura del autor, que perfila su imagen en función de su capacidad de raciocinio, no atada a las autoridades librarias, sino fundamentada sobre el conocimiento práctico, la reflexión y el discurso demostrativo de las ciencias de la naturaleza. La pretendida utilidad de ambos papeles, consistente en desterrar los prejuicios y la superstición generalizada, que no solo se atribuyen al siempre mencionado vulgo, sitúa al autor como fuente distinguida de conocimiento, aunque sea por su intento metodológico y apegado a lo natural, de explicar los fenómenos que son objeto de comidilla y controversia en manos de los devotos y aprensivos ignorantes.

Especialmente se percibe el carácter reivindicativo en las Noches alegres $y$ festivas, donde el Piscator clama en defensa del carácter utilitario y lúdico que atraviesa sus almanaques y defiende asimismo la relatividad de sus predicciones y su propio descreimiento, no ya solo de estos, sino también de las posibilidades de la ciencia misma. No obstante, aunque en Desengaños razonables no encontramos tan directamente la vindicación del personaje, desde el primer momento el yo del autor insiste en su independencia, en el valor de la experiencia y en la propia elaboración del discurso a partir de la observación y de su razón (destacada desde el mismo rótulo), recalcando que expone lo que «discurro", lo que "pienso" y, burlonamente, lo que "pronostico». 


\section{Conclusiones}

Así pues, como hemos visto, Torres actualiza su figura a lo largo de su vida y obra en función de sus intereses de autorrepresentación y a partir de la imagen pública que ha adquirido, atendiendo a los feedbacks que le proporcionan sus lectores y sus críticos. El éxito de sus pronósticos catapultó al escritor a la esfera pública y le reportó fama y dinero, lo que a su vez le costó sucesivas diatribas en las que se le acusó de engañar y extender la superstición entre el vulgo. Aunque Torres protestara ante las censuras hacia sus almanaques y hacia su persona, tuvo la habilidad de encauzar las críticas y aprovecharlas en su propio beneficio, llegando a integrarlas estratégicamente en su proyección autorial. Esto fue así, casi desde un primer momento, en tanto que le permitió atribuir las críticas a la ignorancia de unos adversarios envidiosos de su éxito, probado por la fortuna de sus impresos en el mercado; además, terminó Torres por agradecer a sus enemigos las nuevas ganancias, pues le daban motivo para dar a la imprenta papeles en su defensa. Pero también suma el autor su faceta de escritor divulgativo al incorporarse a una tendencia del momento que le permitía redirigir su proyección y añadir una función que parecía quedar legitimada por su condición de profesor y catedrático.

Aunque su oficio almanaquero le pesó durante su vida y tras su muerte, en sus obras "de desengaño» reclama Torres el reconocimiento de su actividad científica y su incorporación al pensamiento moderno. Todo ello lo hace proclamando con insistencia su independencia de juicio y cuestionando las autoridades en cuanto a la filosofía natural, y especialmente apelando a la observación, experiencia y demostración de las verdades (con lo que reivindica su ciencia - de la que él no vive, según señala, pues le basta su escritura- frente a otras al menos tan susceptibles de error como la suya).

No obstante, aunque Torres incorpora nuevas pinceladas a su autorrepresentación, no por ello desdeña su vertiente almanaquera, sino que pretende legitimar el componente científico de sus pronósticos y poner de relieve el carácter lúdico y literario de sus polémicos vaticinios. Construye, en su conjunto, una imagen sustentada sobre la variedad de oficios y de planos, imagen dinámica cuyos trazos se reescriben y perfilan en las distintas entregas, que explota la individualidad y vanidad de su autor, a través de esa doble ponderación de su imaginación (ligada a la inventiva, a la ficción, a su capacidad creativa y a lo literario) y de su razón (con que aspira a acreditarse como "científico»). 
